\title{
Expression and Significance of Cyclophilin J in Primary Gastric Adenocarcinoma
}

\author{
ZHAOHUA GONG ${ }^{1 *}$, YULING MU ${ }^{2 *}$, JIAN CHEN $^{1,3}$, HONGJIN CHU $^{3}$, PEIWEN LIAN $^{3}$, \\ CONGCONG WANG ${ }^{1}$, JIAHUI WANG ${ }^{3}$ and LIXIN JIANG ${ }^{4}$ \\ Departments of ${ }^{1}$ Oncology and ${ }^{4}$ Gastrointestinal Surgery, and ${ }^{3}$ Central Laboratory, \\ The Affiliated Yantai Yuhuangding Hospital of Qingdao University, Yantai, P.R. China; \\ ${ }^{2}$ Medical School, Binzhou Medical University, Yantai, P.R. China
}

\begin{abstract}
Background/Aim: Biomarkers are essential in early diagnosis and understanding of the molecular mechanism of human cancer. The expression of cyclophilin $J$, a novel member of the cyclophilin family, was investigated in primary gastric adenocarcinoma. Materials and Methods: Western blot analysis was carried out on 36 paired tumor and normal tissue samples; immunohistochemical analysis was carried out on 120 gastric carcinoma tissues and normal adjacent tissue. Results: Cyclophilin $J$ protein was overexpressed in $72.2 \%$ of gastric carcinoma tissues compared to adjacent normal tissues. Immunohistochemical analysis revealed that cyclophilin $J$ was overexpressed in $49.2 \%$ (59/120) and 23.3\% (28/120) of gastric carcinoma tissues and adjacent tissues, respectively $(p<0.05)$. Expression of cyclophilin $J$ was associated with the degree of differentiation, but not with lymph node metastasis, gender or depth of tumor infiltration. The overall survival of patients showed no association with the overexpression of cyclophilin J protein. Conclusion: Cyclophilin J expression was up-regulated in gastric carcinoma compared to normal gastric tissues. However, in order to confirm its association with the survival of patients with gastric cancer, more cases need to be studied.
\end{abstract}

Gastric cancer is the third most common cause of cancerassociated mortality worldwide, responsible for approximately 723,000 deaths annually for both sexes (1). As an important form of cancer of the upper gastrointestinal tract, which also

*These Authors contributed equally to this study.

Correspondence to: Dr. Lixin Jiang, Department of Gastrointestinal Surgery, The Affiliated Yantai Yuhuangding Hospital of Qingdao University, 20 Yuhuangding East Road, Yantai, Shandong Provence, 264000, P.R. China. Tel: +86 18660568896, e-mail: jianglixin1969@ hotmail.com

Key Words: Gastric adenocarcinoma, cyclophilin J, tumor markers. includes the esophageal and esophagogastric junction, gastric cancer presents a major health problem. A dramatic shift in the histology and location of upper gastrointestinal tract tumors has been identified in the USA and Europe (2-4). The most common sites of gastric cancer are the cardia and the esophagogastric junction (2). The morbidity rate of proximal stomach cancer has increased rapidly compared with other malignant tumors in numerous countries (5-7). In developed countries, the morbidity rate of cardia cancer follows that of esophageal cancer (8-10). The reasons for this may be related to the changes in people's lifestyle and eating habits.

In contrast to Western countries, non-proximal stomach cancer is the major form of gastric cancer in East Asia, including Japan, China and other countries (11). The incidence of gastric cancer is evidently regionally distributed, and is more prevalent in East Asia, Eastern Europe and Central and South America (12). According to the World Cancer Report 2014, digestive tract tumors are associated with the highest morbidity rate among all cancer types in China, with gastric cancer and esophageal cancer being the most significant threats (13). Unfortunately, the rate of early diagnosis of gastric cancer is less than $10 \%$ in developing countries $(14,15)$, and due to its high risk and poor survival rate, a continuous endeavor to improve patient outcomes is of great importance.

Surgery is the mainstay of treatment for gastric malignancy (16). Introduction of laparoscopic surgery has improved short-term postoperative outcomes. However, hyperthermic intraperitoneal chemotherapy has not been shown to be beneficial in peritoneal metastatic disease. Recent studies have demonstrated that preoperative and perioperative chemotherapy improves the clinical outcome for patients with gastric cancer (17). Patients with potentially resectable tumors are treated with surgery and perioperative chemotherapy or postoperative chemoradiation; in cases with metastatic involvement, patients are treated with combination chemotherapy as exposure to cytotoxins prolongs survival and improves control of symptoms (18). 
Table I. Baseline characteristics of patients with gastric carcinoma $(n=120)$.

\begin{tabular}{|c|c|c|c|c|c|c|c|}
\hline \multirow[t]{2}{*}{ Clinicopathological features } & \multirow[t]{2}{*}{$\mathrm{n}(\%)$} & \multicolumn{4}{|c|}{ СурJ } & \multirow[t]{2}{*}{ Chi-square value } & \multirow[t]{2}{*}{$p$-Value } \\
\hline & & - & + & ++ & +++ & & \\
\hline \multicolumn{8}{|l|}{ Gender } \\
\hline Male & $86(71.7)$ & 44 & 10 & 30 & 2 & 0.03 & 0.511 \\
\hline Female & $34(28.3)$ & 18 & 1 & 13 & 2 & & \\
\hline \multicolumn{8}{|l|}{ Age } \\
\hline$\geq 55$ Years & $90(75.0)$ & 46 & 7 & 34 & 3 & 0.01 & 0.542 \\
\hline$<55$ Years & $30(25.0)$ & 15 & 4 & 9 & 2 & & \\
\hline \multicolumn{8}{|l|}{ Differentiation } \\
\hline Moderate/high & $30(25.0)$ & 5 & 10 & 13 & 2 & 4.16 & 0.041 \\
\hline Low & $90(75.0)$ & 33 & 24 & 33 & 0 & & \\
\hline \multicolumn{8}{|l|}{ Depth of invasion } \\
\hline Mucosa, submucosa & $26(21.7)$ & 14 & 2 & 9 & 1 & 0.05 & 0.938 \\
\hline Muscular layer & $14(11.7)$ & 7 & 1 & 6 & 0 & & \\
\hline Serosa, visceral peritoneum & $80(66.7)$ & 42 & 6 & 31 & 1 & & \\
\hline \multicolumn{8}{|l|}{ Lymphatic metastasis } \\
\hline Yes & $67(55.8)$ & 34 & 10 & 17 & 6 & 0.03 & 0.500 \\
\hline No & $53(44.2)$ & 26 & 6 & 18 & 3 & & \\
\hline
\end{tabular}

CypJ: Cyclophilin J.

Considering the increased morbidity and mortality associated with gastric cancer in China, the development of efficient and cost-effective immunoassays for the serological diagnosis and prognosis of gastric cancer, and more effective cancer treatment drugs are required. Previously, comparative proteomics of protein extracts obtained from primary tumors and the adjacent normal tissues were used to identify novel cancer markers (19). Cyclophilins belong to a large family of highly conserved ubiquitous peptidyl-prolyl cis-trans isomerases. Cyclophilins have also been identified as specific receptors for the immunosuppressive drug cyclosporine A and are involved in a variety of biological functions (20). At present, at least 16 members of the cyclophilin family have been found to be expressed in human cells (21).

Cyclophilin A, which was identified in 1984, is the earliest discovered member of the cyclophilin family (22). Cyclophilin has been shown to be expressed differentially between cancer and normal tissues, including lung, breast, gastric and pancreatic cancer (23-26). Peptidylprolyl isomerase-like 3 , cyclophilin $\mathrm{J}$, which has $50 \%$ sequence homology to cyclophilin A, was first indicated to be encoded by a cyclophilin-like gene in the human fetal brain (27). The association between cyclophilin J expression and tumor remains unknown. The present study aimed to detect the expression of cyclophilin $\mathrm{J}$ in gastric cancer and adjacent tissues using immunohistochemical methods, which will provide a basis for the additional exploration of cyclophilin $\mathrm{J}$.

\section{Materials and Methods}

Clinical specimens. The study was approved by the Ethics Committee of Yantai Yuhuangding Hospital and written informed consent was obtained from all patients for voluntary participation. Frozen tissues samples, paraffin-embedded gastric adenocarcinoma samples and paired adjacent tissues were obtained from patients with gastric cancer who were treated by surgery at the Yantai Yuhuangding Hospital between January 2014 and December 2015. None of the patients received any preoperative antitumor treatment. The clinical features of each case were recorded and analyzed.

In total, 36 tissue samples (18 tumor tissues and 18 adjacent normal tissues) obtained from 18 patients with gastric cancer were immediately frozen at $-80^{\circ} \mathrm{C}$ subsequent to resection. A total of 120 paraffin-embedded gastric adenocarcinoma samples were obtained from 70 male and 50 female patients aged between 26 and 79 years old (median $=59$ years), with 88 patients $>55$ years old. The clinicopathological variables of each patient including gender, age, differentiation, infiltration and lymphatic metastasis are summarized in Table I. All gastric carcinoma patients were followed up for 2 years subsequent to surgery.

Western blot analysis. Tissue samples were ground in liquid nitrogen and lysed in radio-immunoprecipitation assay lysis buffer $(100 \mathrm{mM}$ Tris- $\mathrm{HCl}, 0.15 \mathrm{mM} \mathrm{NaCl}, 0.5$ ethylene diamine tetra-acetic acid, $20 \%$ Tergitol-type NP-40, 0.1 M NaPPi, $0.1 \mathrm{M} \mathrm{NaVO}_{3}$ ). The protein lysate $(15 \mu \mathrm{g})$ was subject to $5-12 \%$ sodium dodecyl sulfate-polyacrylamide gel electrophoresis and then transferred to a polyvinylidene fluoride membrane (EMD Millipore, Billerica, MA, USA). The membrane was incubated with polyclonal rabbit anti-human anti-cyclophilin J (dilution, 1:400; Sigma-Aldrich, St. Louis, MO, USA) at $4^{\circ} \mathrm{C}$ overnight. The membrane was then washed three times, for 10 minutes each time, with $0.1 \%$ Tween-20 Tris-buffered saline and incubated with HRP-linked 

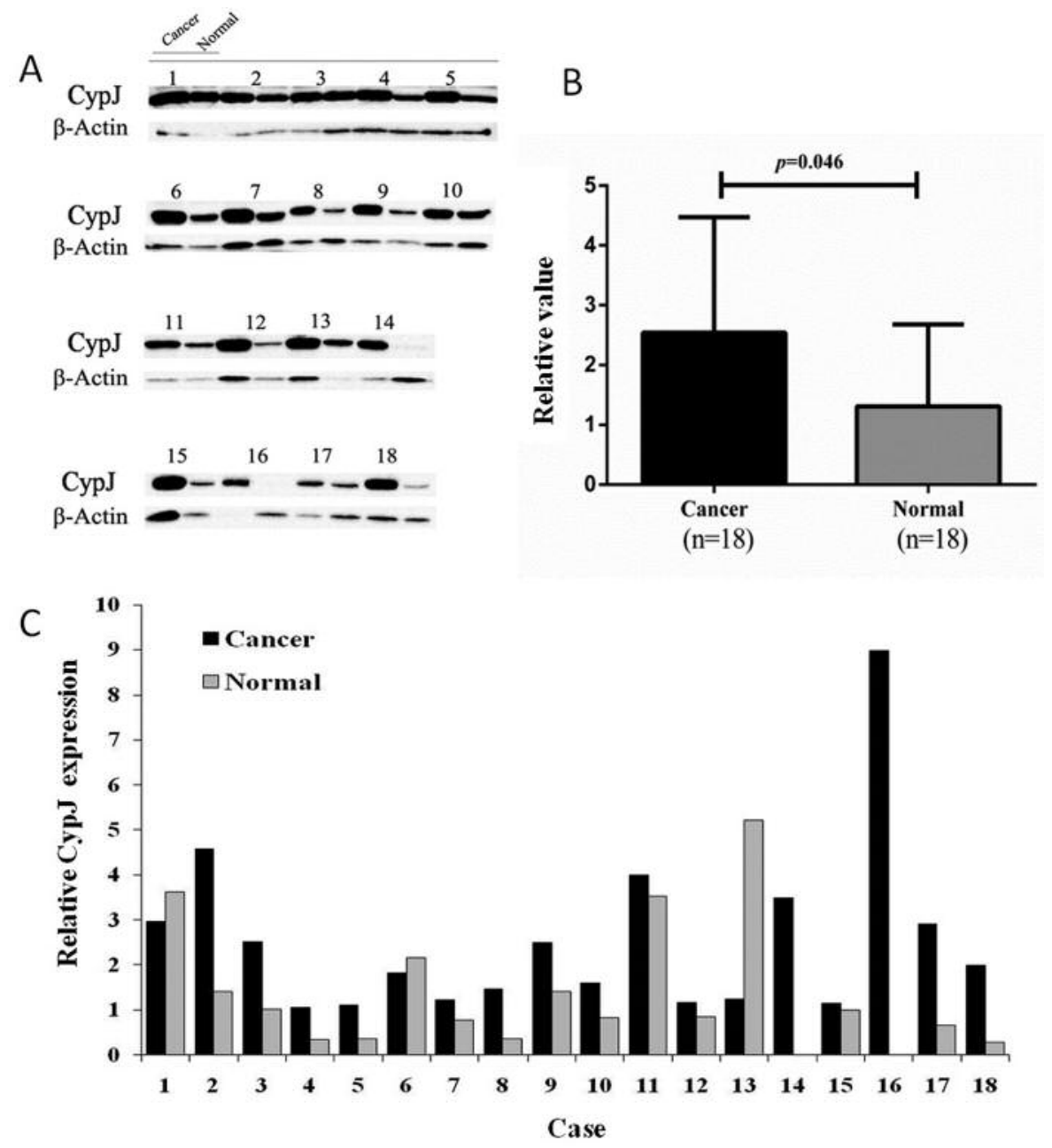

Figure 1. A: Western blot analysis of cyclophilin J protein in 18 matched pairs of gastric carcinoma and adjacent normal tissue samples. $\beta$-Actin was used as internal control. B: Expression of cyclophilin $J$ was significantly higher in tumor than in adjacent normal tissue. C: Densitometric analysis of cyclophilin J protein in 18 matched pairs of samples. Cyclophilin J was overexpressed in 15 samples in cancer compared to normal tissue.

goat anti-mouse IgG and goat anti-rabbit IgG secondary antibody (dilution, 1:5,000; Invitrogen; Thermo Fisher Scientific, Inc., Waltham, MA, USA) for 1 hour at room temperature. Finally, the blots were visualized by chemiluminescence detection using an enhanced chemiluminescence plus kit (Thermo Fisher Scientific, Inc.) and exposed to X-ray film (Kodak, Rochester, NY, USA). Subsequent to scanning, the images were analyzed using ImageJ $1.48 \mathrm{v}$ (National Institutes of Health, USA; http://imagej.nih.gov/ij/download.html).

The expression level of cyclophilin $\mathrm{J}$ was normalized against that of $\beta$-actin. The expression ratio (ER) between the cancer and normal tissues was calculated for each pair of samples as $\mathrm{ER}=(\mathrm{IPC} / \mathrm{IPN}) /$ (IAC/IAN), where IPC and IPN denoted the measured intensity integral of the cyclophilin $\mathrm{J}$ protein band for gastric cancer and adjacent normal tissue, respectively, and IAC and IAN denoted the measured intensity integral of the $\beta$-actin band for cancer and adjacent normal tissue, respectively. The intensity integral of the cyclophilin J protein band was measured with Image J. A value of
ER $>1.1$ defined overexpression in cancer and $E R<0.9$ defined decreased expression in cancer, respectively.

Immunohistochemistry. The gastric carcinoma tissues were fixed in $4 \%$ formalin for at least $24 \mathrm{~h}$, washed with $0.9 \% \mathrm{NaCl}$, and processed with ethanol and xylene solutions. The preparations were then embedded in paraffin, cut into $4-\mu \mathrm{m}$ thick sections, and mounted on glass slides following conventional procedures. The sections were rinsed in phosphate buffered saline (PBS) (Biorbyt, Cambridge, UK) for $15 \mathrm{~min}$ and boiled in citrate buffer ( $\mathrm{pH} \mathrm{6.0)}$ (Biorbyt) for 15 minutes for antigen retrieval. The slides were then blocked with $3 \% \mathrm{H}_{2} \mathrm{O}_{2}$ solution (Sigma-Aldrich) and incubated at $4^{\circ} \mathrm{C}$ overnight with polyclonal rabbit anti-human anti-cyclophilin $\mathrm{J}$ (dilution, 1:40; Abcam, Cambridge, UK). Samples were then washed with PBS and incubated in biotinylated goat anti-rabbit IgG secondary antibody (dilution, 1:200; Invitrogen; Thermo Fisher Scientific, Inc.) for 1 hour at room temperature. 

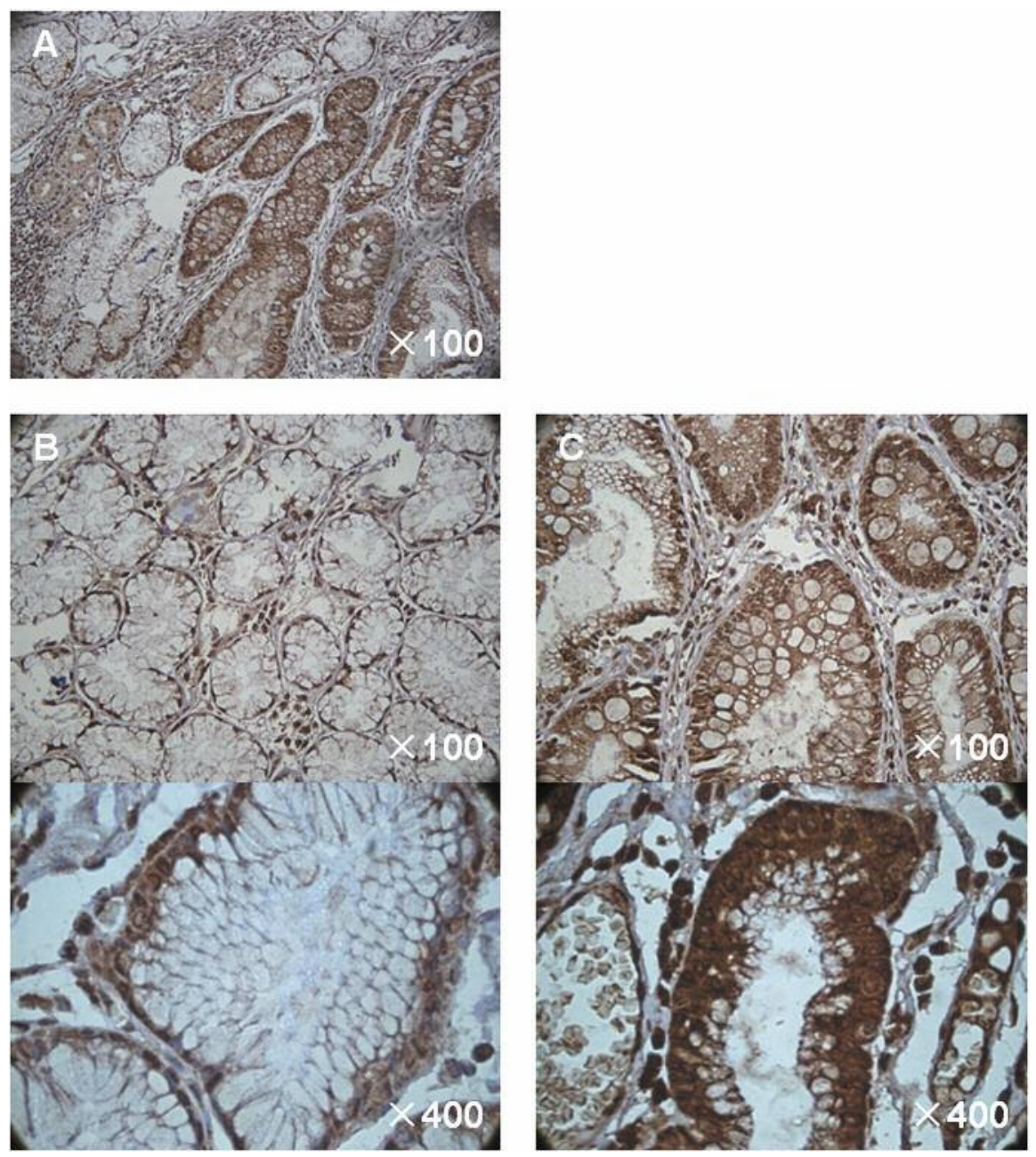

Figure 2. Immunohistochemical analysis of cyclophilin J. A: Expression of cyclophilin $J$ in tumor cells of gastric adenocarcinoma and adjacent normal tissue cells. B: Cytoplasmic and nuclear expression of cyclophilin J in gastric adenocarcinoma cells. C: Nuclear expression of cyclophilin $J$ in normal tissues. Diaminobenzidine and eosin stain.

Development of the slides using DAB kit (ZSGB-BIO., Beijing, P.R. China) and counterstaining with hematoxylin (MCE, Shanghai, P.R. China) resulted in the visualization of the immunostaining. Finally, tissue sections were dehydrated with $100 \%$ ethanol (AccuStandard, New Haven, CT, USA) and xylene (TRC, Toronto, Canada). For the negative control, PBS was used instead of the primary antibodies.

The immunolabeled specimens were observed under an Olympus BX51 microscope (Olympus Corporation, Tokyo, Japan) equipped with a DP72 camera (Olympus Corporation). Two pathologists, using a blind method, evaluated the immunohistochemical staining. Positive staining showed a brown-yellow color reaction; in gastric carcinoma tissues, the cytoplasm and nuclei showed positive immunostaining for cyclophilin J. A dual semi-quantitative scale combining staining intensity and percentage of positively stained cells was used to evaluate cyclophilin J protein staining. The staining intensity was scored as 0 (negative), 1 (weak), 2 (moderate), or 3 (strong). The percentage of positively stained cells was scored as follows: 0 , no staining or staining in $<5 \%$ of tumor cells; 1 , staining in $5 \%$ to $25 \%$ of cells; 2 , staining in $26 \%$ to $50 \%$ of cells; 3 , staining in $51 \%$ to $75 \%$ of cells; and 4 , staining in $>75 \%$ of cells. For each section, five randomly selected fields were examined at $\times 400$ magnification with an Olympus BX51 light microscope and 100 carcinoma cells were counted for each field. Positive expression was observed as diffuse cytoplasmic and nucleic brown-yellow or yellow particles. The final score was the product of the staining intensity and percentage of positive cells, scores of 0-3 denote negative expression, while scores of 4-12 denote positive expression.

Statistics. The chi-squared test was performed to calculate the statistical significance of associations of the variables using SPSS version 13.0 (SPSS Inc., Chicago, IL, USA). A p-value of less than 0.05 was considered to indicate a statistically significant difference. The Kaplan-Meier method was used to plot survival curves, and differences were compared using the log-rank test $(p<0.05)$. 


\section{Results}

The expression of the cyclophilin $\mathbf{J}$ protein in gastric tumor and adjacent normal tissue samples of 18 patients with gastric carcinoma was tested using western blot analysis. The results revealed an ER $>1.1$ in 15 patients $(15 / 18 ; 83.3 \%)$ and an ER $<0.9$ in three patients $(3 / 18 ; 16.7 \%)$ (Figure 1A). The cyclophilin $\mathrm{J}$ protein was shown to be significantly overexpressed in gastric carcinoma tissues compared with the adjacent normal tissues (Figure 1B). The clinicopathological factors, including gender, age, differentiation, infiltration and lymphatic metastasis, of the patients were analyzed. No association with the expression of cyclophilin $\mathrm{J}$ in tumors was identified.

The expression of cyclophilin $\mathrm{J}$ protein in the paraffinembedded tumor tissues of patients with gastric cancer was analyzed by immunohistochemical staining. In gastric cancer cells, cyclophilin $\mathrm{J}$ protein was expressed in the cytoplasm and nucleus, while in normal stomach cells cyclophilin $\mathrm{J}$ was mainly expressed in the cytoplasm (Figure 2). The rate of positivity for cyclophilin $\mathrm{J}$ protein in gastric carcinoma tissues was significantly higher than that in adjacent tissues [49.2\% $(59 / 120)$ versus $23.3 \%$ (28/120), respectively; $p<0.05]$.

The association between cyclophilin $\mathrm{J}$ expression and the clinicopathological characteristics of gastric carcinoma, including gender, age, and degree of differentiation, lymphatic metastasis and depth of infiltration were analyzed The expression of cyclophilin $\mathbf{J}$ was associated with the degree of tumor differentiation $(p=0.041$; Table I), but not with the other parameters. All patients with gastric carcinoma who were untreated prior to surgery were followed-up for 2 years subsequent to surgery. No statistically significant association between cyclophilin $\mathrm{J}$ expression and overall survival was found ( $p=0.995$; Figure 3 ).

\section{Discussion}

Despite the development of diagnostic techniques and treatment methods for gastric carcinoma, the majority of patients are diagnosed with disease at an advanced stage (4). As a consequence, the 5-year survival rate is extremely poor, at $<10 \%$ (13). Late diagnosis is partly due to a lack of identified diagnostic markers and efficient monitoring methods for cancer progression at an early stage, although a few tumor markers have been used in gastric carcinoma, including carcinoembryonic antigen 19-9 and the DR70 fibrin degradation product. In the present study, cyclophilin $\mathrm{J}$ was indicated as being overexpressed in gastric carcinoma tissues compared to normal tissues, and a significant association was identified between increased levels of cyclophilin $\mathrm{J}$ expression and tumor differentiation. The up-regulation of cyclophilin $\mathrm{J}$ expression in patients may be used as a clinical biomarker for the diagnosis and assessment of gastric cancer.

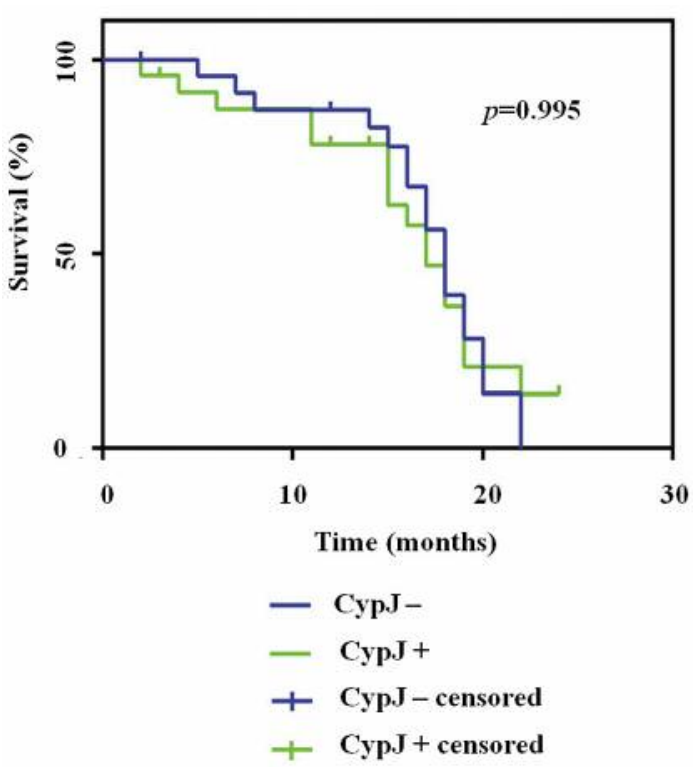

Figure 3. Comparison of survival pattern of the participants according to cyclophilin J (CypJ) expression. The outcome of 2 years of follow-up of all patients was analyzed using a Kaplan-Meier curve. No statistical difference in overall survival was noted between the group of patients with cyclophilin $J$ overexpression (CypJ+) and the group that did not express cyclophilin J (CypJ-).

Huang et al. studied the structure of human cyclophilin $\mathrm{J}$ and found that cyclophilin $\mathrm{J}$ demonstrated $50 \%$ sequence homology to human cyclophilin A (27). Based on their similar sequences, cyclophilin $\mathrm{J}$ was hypothesized to be associated with tumorigenesis. Campa et al. identified cyclophilin A as a potential molecular target in non-small cell lung cancer due to its up-regulation (28).

In the present study, results of western blot and immunohistochemical analysis clearly demonstrated increased cyclophilin $\mathrm{J}$ expression in gastric tumors compared with adjacent normal tissues. Cyclophilin $\mathrm{J}$ was also overexpressed in $83.3 \%$ of moderately and highly differentiated gastric tumors as opposed to $63.3 \%$ of poorlydifferentiated gastric tumors $(p<0.05$; Figure 1C). These results suggest that cyclophilin $\mathrm{J}$ may be involved in the tumorigenesis of gastric carcinoma. However, the exact molecular mechanism for the involvement of cyclophilin $\mathbf{J}$ in stomach cancer remains to be fully studied.

Controversies exist in regards to the prognostic significance of cyclophilin A overexpression in various tumors. Li et al. suggested that cyclophilin A may act as a novel prognostic factor due to an association between cyclophilin A overexpression and decreased survival (29). However, Howard et al. suggested that there was no statistically significant association between cyclophilin A expression and the overall 
survival of patients (30). In the present study, no statistical significance in the association between cyclophilin $\mathrm{J}$ overexpression and overall survival was observed.

In conclusion, the results of the present study demonstrated that cyclophilin $\mathrm{J}$ expression was up-regulated in gastric carcinoma tissues. This phenomenon may be closely associated with the tumorigenesis and progression of gastric carcinoma. Therefore, the inhibition of cyclophilin J activity may act as an effective method for the treatment of gastric tumors, although additional clinical studies are required to support this assumption.

\section{Acknowledgements}

This work was supported by the National Natural Science Foundation of China (81071758); Shandong Science and Technology Development Project (2015GSF118142); Shandong Medicine and Health Science Technology Program (2016WS0706); China International Medical Foundation (Z20140615325); Natural Science Foundation of Shandong Province Joint Programme (ZR2016HL26, ZR2015HL069); and YantaiYuhuangding Hospital Initiative Foundation for Young Scientist (201526, 201402); Yantai Science and Technology Program (2016WS013, 2015WS018, 1605350099).

\section{References}

1 Guedes MT, de Jesus JP, de Souza Filho O, Fontenele RM and Sousa AI: Clinical and epidemiological profile of cases of deaths from stomach cancer in the National Cancer Institute, Brazil. E Cancer Med Sci 8: 445-454, 2014.

2 Johnston BJ and Reed PI: Changing pattern of oesophageal cancer in a general hospital in the UK. Eur J Cancer Prev 1: 2325, 1991.

3 Blot WJ, Devesa SS, Kneller RW and Fraumeni JF Jr.: Rising incidence of adenocarcinoma of the esophagus and gastric cardia. JAMA 265: 1287-1289, 1991.

4 Powell $\mathrm{J}$ and McConkey CC: Increasing incidence of adenocarcinoma of the gastric cardia and adjacent sites. Br J Cancer 62: 440-443, 1990.

5 Hansson LE, Sparén P and Nyrén O: Increasing incidence of carcinoma of the gastric cardia in Sweden from 1970 to 1985. Br J Surg 80: 374-377, 1993.

6 Hansen S, Wiig JN, Giercksky KE and Tretli S: Esophageal and gastric carcinoma in Norway 1958-1992: Incidence time trend variability according to morphological subtypes and organ subsites. Int J Cancer 71: 340-344, 1997.

7 Thomas RJ, Lade S, Giles GG and Thursfield V: Incidence trends in oesophageal and proximal gastric carcinoma in Victoria. Aust N Z J Surg 66: 271-275, 1996.

8 Crew KD and Neugut AI: Epidemiology of upper gastrointestinal malignancies. Semin Oncol 31: 450-464, 2004.

9 Kubo A and Corley DA: Marked regional variation in adenocarcinomas of the esophagus and the gastric cardia in the United States. Cancer 95: 2096-2102, 2002.

10 Powell J, McConkey CC, Gillison EW and Spychal RT: Continuing rising trend in oesophageal adenocarcinoma. Int $\mathrm{J}$ Cancer 102: 422-427, 2002.
11 Parkin DM and Muir CS: Cancer incidence in five continents. Comparability and quality of data. IARC Sci Publ 120: 45-173, 1992.

12 Torre LA, Bray F, Siegel RL, Ferlay J, Lortet-Tieulent J and Jemal A: Global cancer statistics, 2012. CA Cancer J Clin 65: 87-108, 2015.

13 McGuire S: World Cancer Report 2014. Geneva, Switzerland: World Health Organization, International Agency for Research on Cancer, WHO Press, 2015. Adv Nutr 7(2): 418-419, 2016.

14 Peddanna N, Holt S and Verma RS: Genetics of gastric cancer. Anticancer Res 15: 2055-2064, 1995.

15 Huang JR and Huang ZG: Research progress in screening of early gastric cancer. J Practical Oncol 27: 1-4, 2012 (in Chinese).

16 Tegels J, De Maat M, Hulsewé K, Hoofwijk A and Stoot J: Improving the outcomes in gastric cancer surgery. World $\mathrm{J}$ Gastroenterol 20(38): 13692-13704, 2014.

17 Aichler M, Luber B, Lordick F and Walch A: Proteomic and metabolic prediction of response to therapy in gastric cancer. World J Gastroenterol 20(38): 13648-13657, 2014.

18 Van Cutsem E, Moiseyenko VM, Tjulandin S, Majlis A, Constenla M, Boni C, Rodrigues A, Fodor M, Chao Y, Voznyi E, Risse ML and Ajani JA: Phase III study of docetaxel and cisplatin plus fluorouracil compared with cisplatin and fluorouracil as first-line therapy for advanced gastric cancer: a report of the V325 Study Group. J Clin Oncol 24: 4991-4997, 2006.

19 Liu W, Yang Q, Liu B and Zhu Z: Serum proteomics for gastric cancer. Clin Chim Acta 431: 179-84, 2014.

20 Roy S, Basu S, Datta AK, Bhattacharyya D, Banerjee R and Dasgupta D: Equilibrium unfolding of cyclophilin from Leishmania donovani: Characterization of intermediate states. Int J Biol Macromol 69: 353-360, 2014.

21 Nigro P, Pompilio G and Capogrossi MC: Cyclophilin A: A key player for human disease. Cell Death Dis 4: e888, 2013.

22 Handschumacher RE, Harding MW, Rice J, Drugge RJ and Speicher DW: Cyclophilin: A specific cytosolic binding protein for cyclosporin A. Science 226: 544-547, 1984.

23 Qian Z, Zhao X, Jiang M, Jia W, Zhang C, Wang Y, Li B and Yue W: Down-regulation of cyclophilin A by siRNA diminishes non-small cell lung cancer cell growth and metastasis via the regulation of matrix metallopeptidase 9. BMC Cancer 12: 442452, 2012.

24 Chevalier F, Depagne J, Hem S, Chevillard S, Bensimon J, Bertrand $\mathrm{P}$ and Lebeau $\mathrm{J}$ : Accumulation of cyclophilin $\mathrm{A}$ isoforms in conditioned medium of irradiated breast cancer cells. Proteomics 12: 1756-1766, 2012.

25 Grigoryeva ES, Cherdyntseva NV, Karbyshev MS, Volkomorov VV, Stepanov IV, Zavyalova MV, Perelmuter VM, Buldakov MA, Afanasjev SG, Tuzikov SA, Bukurova YA, Lisitsyn NA and Beresten SF: Expression of cyclophilin $\mathrm{A}$ in gastric adeno-carcinoma patients and its inverse association with local relapses and distant metastasis. Pathol Oncol Res 20: 467-473, 2014.

26 Shen J, Person MD, Zhu J, Abbruzzese JL and Li D: Protein expression profiles in pancreatic adenocarcinoma compared with normal pancreatic tissue and tissue affected by pancreatitis as detected by two-dimensional gel electrophoresis and mass spectrometry. Cancer Res 64: 90189026, 2004.

27 Huang LL, Zhao XM, Huang CQ, Yu L and Xia ZX: Structure of recombinant human cyclophilin $\mathrm{J}$, a novel member of the 
cyclophilin family. Acta Crystallogr D Biol Crystallogr 61: 316 321, 2005.

28 Campa MJ, Wang MZ, Howard B, Fitzgerald MC and Patz EF Jr.: Protein expression profiling identifies macrophage migration inhibitory factor and cyclophilin a as potential molecular targets in non-small cell lung cancer. Cancer Res 63: 1652-1656, 2003.

29 Li Z, Zhao X, Bai S, Wang Z, Chen L, Wei Y and Huang C: Proteomics identification of cyclophilin a as a potential prognostic factor and therapeutic target in endometrial carcinoma. Mol Cell Proteomics 7: 1810-1823, 2008.
30 Howard BA, Zheng Z, Campa MJ, Wang MZ, Sharma A, Haura E, Herndon JE II, Fitzgerald MC, Bepler G and Patz EF Jr.: Translating biomarkers into clinical practice: Prognostic implications of cyclophilin A and macrophage migratory inhibitory factor identified from protein expression profiles in non-small cell lung cancer. Lung Cancer 46: 313-323, 2004.

Received June 1, 2017

Revised June 23, 2017

Accepted June 27, 2017 